\title{
A population-based dietary inflammatory index predicts levels of C-reactive protein in the Seasonal Variation of Blood Cholesterol Study (SEASONS)
}

\author{
Nitin Shivappa ${ }^{1,2}$, Susan E Steck ${ }^{1,2}$, Thomas G Hurley ${ }^{1}$, James R Hussey ${ }^{2}$, \\ Yunsheng $\mathrm{Ma}^{3}$, Ira S Ockene ${ }^{4}$, Fred Tabung ${ }^{1,2}$ and James R Hébert ${ }^{1,2, *}$ \\ ${ }^{1}$ Cancer Prevention and Control Program, University of South Carolina, 915 Greene Street, Suite 241, \\ Columbia, SC 29208, USA: ${ }^{2}$ Department of Epidemiology and Biostatistics, Arnold School of Public Health, \\ University of South Carolina, Columbia, SC, USA: ${ }^{3}$ Division of Preventive and Behavioral Medicine, Department \\ of Medicine, University of Massachusetts Medical School, Worcester, MA, USA: ${ }^{4}$ Division of Cardiovascular \\ Medicine, Department of Medicine, University of Massachusetts Medical School, Worcester, MA, USA
}

Submitted 5 March 2013: Final revision received 6 June 2013: Accepted 22 July 2013: First published online 10 October 2013

\begin{abstract}
Objective: To perform construct validation of the population-based Dietary Inflammatory Index (DII) using dietary data from two different dietary assessments and serum high-sensitivity C-reactive protein (hs-CRP) as the construct validator. Design: Using data derived from (i) three $24 \mathrm{~h}$ dietary recalls (24HR) at baseline and at the end of each subsequent quarter (i.e. up to fifteen over a year) and (ii) a $7 \mathrm{~d}$ dietary recall (7DDR) measured at baseline and then quarterly, regression analyses were conducted to test the effect of the DII score on serum hs-CRP as dichotomous ( $\leq 3 \mathrm{mg} / 1,>3 \mathrm{mg} / 1)$, while controlling for important potential confounders.

Setting: Existing data from the Seasonal Variation of Blood Cholesterol Study (SEASONS), a longitudinal observational study of healthy participants recruited in Worcester, MA, USA and participants were followed for 1 year.

Subjects: Participants who had at least one hs-CRP measurement over her/his 1-year participation ( $n 495$ for $24 \mathrm{HR}, n 559$ for 7DDR).

Results: Higher DII scores were associated with values of hs-CRP $>3 \mathrm{mg} / 1$ $(\mathrm{OR}=1 \cdot 08 ; 95 \% \mathrm{CI} 1 \cdot 01,1 \cdot 16, P=0.035$ for the $24 \mathrm{HR}$; and $\mathrm{OR}=1 \cdot 10 ; 95 \% \mathrm{CI}$ $1 \cdot 02,1 \cdot 19, P=0 \cdot 015$ for the 7DDR).

Conclusions: The population-based DII was associated with interval changes in hs-CRP using both the 24HR and 7DDR. The success of this first-of-a-kind attempt at relating individuals' intakes of inflammation-modulating foods using this refined DII, and the finding that there is virtually no drop-off in predictive capability using a structured questionnaire in comparison to the $24 \mathrm{HR}$ standard, sets the stage for use of the DII in a wide variety of other epidemiological and clinical studies.
\end{abstract}

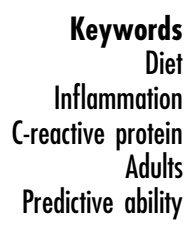

Inflammation is a response due to repeated 'injury', e.g. from cigarette smoking, infection or hypertension, and evidence is accumulating on the role of chronic inflammation in cancer ${ }^{(1)}$, with colon cancer being the most well described ${ }^{(2)}$. The inflammatory microenvironment includes production of cytokines and chemokines that also promote tumour initiation, growth and invasion ${ }^{(3)}$.

The acute-phase protein C-reactive protein (CRP) is produced in response to stimulation by interleukins, such as IL- $6{ }^{(4)}$. Although used as a marker of inflammation in such conditions as rheumatoid arthritis for many decades, the more recent development of a high-sensitivity C-reactive protein (hs-CRP) assay permitted the detection of inflammation at the vascular level ${ }^{(5)}$. Many studies have shown that CRP is associated with a number of CVD end points ${ }^{(6)}$.
In addition, CRP and inflammatory cytokines such as IL-6 and TNF- $\alpha$ are increased among obese individuals, positively correlated with BMI, and central adiposity has been shown to be associated with increased inflammation $^{(7)}$. Higher levels of IL- 6 among obese individuals are associated with insulin resistance ${ }^{(8)}$. Ridker et al. ${ }^{(9)}$ found that each component of the metabolic syndrome (obesity, hypertriacylglycerolaemia, low HDL-cholesterol, hypertension, abnormal glucose metabolism) is significantly associated with higher levels of hs-CRP.

Diet is known to play a major and significant role in the regulation of chronic inflammation. Previous research has shown an inverse association between fruit and vegetable consumption and inflammatory markers such as CRP, IL-6 and TNF- $\alpha^{(10)}$. The 'Western' diet, which is high in red 
meat, high-fat dairy products, refined grains and simple carbohydrates, has been associated with higher levels of CRP and IL- $6^{(11)}$. On the other hand, the Mediterranean diet, which is high in whole grains, fish, fruit and green vegetables, with moderate alcohol and olive oil intakes, and low in red meat and butter, has been associated with lower levels of inflammation ${ }^{(12-16)}$. Diets high in fruits and vegetables have been associated with lower levels of $\mathrm{CRP}^{(17-19)}$. Specific nutrients such as $n-3$ PUFA $^{(20-25)}$, fibre ${ }^{(26-30)}$, moderate alcohol intake $e^{(31-33)}$, vitamin $\mathrm{E}^{(25,34-40)}$, vitamin $C^{(34,41-43)}, \beta$-carotene ${ }^{(25,34,44-46)}$ and magnesium $^{(26,47-49)}$ also have consistently been shown to be associated with lower levels of inflammation.

Over the past three years, we have developed a Dietary Inflammatory Index (DII) that can be used in different data sets across diverse population in order to predict levels of inflammatory markers and related health outcomes ${ }^{(50)}$. We have substantially modified the DII since the original publication in $2009^{(51)}$. As described in a companion article ${ }^{(50)}$, this moves beyond typical dietary indices in the rigour applied to reviewing the literature (nearly 2000 articles were read and scored) and 'anchoring' this to what people actually eat (the final DII is based on actual food consumption data from eleven populations around the world). In this paper, we describe results of fitting this DII to two different sources of dietary intake information in order to predict hs-CRP in a longitudinal study of diet and inflammation.

\section{Materials and methods}

\section{Study design}

Briefly, the Seasonal Variation of Blood Cholesterol Study (SEASONS) was a prospective observational study. A total of 641 healthy participants were followed for 1 year, with data obtained at baseline and then every 3 months, within a 3-week window on either side of the individual's quarterly appointment date, to the 1-year anniversary point (total of five assessments). Eligibility criteria included being a resident of Worcester County (MA, USA), age 20-70 years and having telephone service. Study participants were not taking cholesterol-lowering medications (e.g. statins) and were not actively on lipid-lowering or weight-control diets, did not have possible causes of secondary hyperlipidaemia, had not been diagnosed as having CHD, and were free of life-threatening illness. Individuals were recruited between December 1994 and February 1997 and enrolment occurred throughout the calendar year. The Institutional Review Boards of the Fallon Healthcare System and the University of Massachusetts Medical School approved all subject recruitment and data collection procedures. Each individual signed an approved informed consent form before entering the study.

The SEASONS data set was selected for testing the DII for two reasons: (i) it had extremely high-quality data on individual-level exposure to food parameters; and (ii) it had hs-CRP data corresponding to each dietary measure. Details of the SEASONS are provided elsewhere ${ }^{(52,53)}$.

Eligible participants were scheduled for an in-clinic appointment. At the first visit, previously completed questionnaires were obtained, anthropometric measurements were taken and a fasting blood sample was drawn. Follow-up appointments were scheduled every 3 months for 1 year, for a total of five appointments. There was a 6-week window on both sides of each participant's quarterly appointment during which blood samples were obtained. Considerable information was collected on each participant. Questionnaire-derived data included: demographics, psychosocial measures, social desirability and approval measures, seasonal patterns in mood and behaviour, dietary information in the form of validated $7 \mathrm{~d}$ dietary recalls $(7 \mathrm{DDR})^{(54)}$ and $24 \mathrm{~h}$ recalls $(24 \mathrm{HR})$, and stress measures. Anthropometric measurements included height, weight, waist circumference and hip circumference. Blood pressure also was measured, as were serum hs-CRP and lipids.

\section{Diet and physical activity assessment}

Diet and physical activity were measured using the $24 \mathrm{HR}$ method. A set of three $24 \mathrm{HR}$ was administered on randomly selected days representing two weekdays and one weekend day at baseline and at each subsequent quarter. All dietary $24 \mathrm{HR}$ data were entered and analysed using the Nutrition Data System software (NDS V2·3). Values from the three dietary $24 \mathrm{HR}$ were averaged and these were used to calculate DII, thereby resulting in a single DII score for each individual at baseline and in each quarter. Participants also provided dietary data using the 7DDR. This structured instrument, consisting of questions on the amount (i.e. size and frequency) of consumption of 118 food and thirteen beverage items, was developed by Hebert et al. ${ }^{(54)}$ for use in the Worcester Area Trial for Counseling in Hyperlipidemia (WATCH) study, which was conducted in Greater Worcester, the same region in central Massachusetts in which SEASONS participants were recruited ${ }^{(55,56)}$. While the focus was primarily on parameters that would affect blood lipids, the validation of the instrument indicated that it provides long-term estimates of diet across a wide variety of nutrients ${ }^{(54)}$. The 7DDR is an optically scannable form that is filled out in less than $25 \mathrm{~min}$. The form along with appropriate instructions was mailed to individuals prior to each of the five visits. For the $24 \mathrm{HR}$, we were able to obtain intake values for forty-four of the forty-five food parameters required for DII calculation with the exception of trans-fat, because the version of NDS that was used did not calculate intake of trans-fat. However, owing to limited representation of dietary information on any structured questionnaire, data were available on twenty-eight of the forty-five food parameters for the $7 \mathrm{DDR}^{(54)}$. Physical activity was measured 
as part of the $24 \mathrm{HR}$ interview process using a previously validated method $^{(57)}$, and output as energy expenditure overall and by domain as total metabolic equivalents of task (MET).

\section{Serum collection and laboratory measurements}

Blood was drawn at baseline and quarterly for up to 1 year (a total of five assessment periods). There was a 6-week window around the quarterly appointment to obtain serum samples from participants. This window spanned from 3 weeks before to 3 weeks after the scheduled appointment. Serum hs-CRP was analysed in the laboratory of Dr Nader Rifai at the Children's Hospital, Harvard Medical School, Boston, MA. The methodology was described previously ${ }^{(58)}$. Inter-assay and intra-assay CV for hs-CRP were in compliance with the ranges accepted by the US Centers for Disease Control and Prevention (CDC). Assays for total cholesterol, HDL-cholesterol and TAG were conducted in a CDC Standardized Laboratory ${ }^{(53)}$. LDL-cholesterol was calculated by the Friedewald formula ${ }^{(59)}$. When TAG exceeded $400 \mathrm{mg} / \mathrm{dl}$, LDL-cholesterol was not calculated. Healthy male and female participants who had at least one hs-CRP measurement over her/his entire 1-year participation were included in the analysis.

\section{Statistical analyses}

Summary statistics were used to describe the study population at baseline separately for both $24 \mathrm{HR}$ and 7DDR subsets (as the numbers of participants with complete data from each were unequal; $n 495$ and $n$ 559, respectively). Comparisons of baseline characteristics by sex were made using $\chi^{2}$ tests for categorical variables and two-sample $t$ tests for continuous variables. DII was converted to tertiles and tests for trend across DII tertiles were carried out for age, smoking status, hs-CRP, BMI, $\mathrm{MET} / \mathrm{d}$, LDL-cholesterol and HDL-cholesterol. Generalized linear mixed models (proc GLIMMIX in SAS) were used for more complex analyses. Here, we used a compound symmetry covariance matrix to account for the dependence of observations made on the same individuals. The primary outcome variable for this analysis was hs-CRP, which was dichotomized to $\leq 3 \mathrm{mg} / \mathrm{l}$ and $>3 \mathrm{mg} / \mathrm{l}$, and the odds of elevated hs-CRP ( $>3 \mathrm{mg} / \mathrm{l})$ was determined. Values of hs-CRP $>10 \mathrm{mg} / \mathrm{l}$ were excluded from the total number of observations because this may be a result of acute inflammation; only sixty-five such values ( $3 \%$ of the total) were excluded from the total of 2165 available hs-CRP measures as a consequence of this ${ }^{(60)}$. The primary independent variable was the score obtained from the DII and tertiles of DII. Both unadjusted and adjusted analyses were carried out. We also tested for effect modification between DII score and categories of BMI, age and infection status by including interaction terms in the model. Variables controlled in analyses were age, sex, race, BMI, smoking status, alcohol consumption status, physical activity, marital status, HDL-cholesterol, total cholesterol, anti-inflammatory medication use, light season, herbal supplement use, and a variable indicating if the participant had an infection during the study quarter. Race was dichotomized into 'White' and 'Other' because $90 \%$ of the study population was White. BMI was categorized into normal weight $\left(18.5\right.$ to $\left.<25 \cdot 0 \mathrm{~kg} / \mathrm{m}^{2}\right)$, overweight $\left(25 \cdot 0\right.$ to $\left.<30 \cdot 0 \mathrm{~kg} / \mathrm{m}^{2}\right)$ and obese $\left(\geq 30 \cdot 0 \mathrm{~kg} / \mathrm{m}^{2}\right)$. Participants considered underweight $\left(<18.5 \mathrm{~kg} / \mathrm{m}^{2}\right)$ were excluded from analysis. Smoking status was dichotomized as yes/no. Level of education was categorized into high-school graduate or less, vocational/trade and some college, and college graduate or more. Marital status was categorized into single, married, living with a partner, separated, divorced or widowed. Total cholesterol and HDL-cholesterol were left as continuous variables. Seasons were categorized using the 'light season' definition centred at the equinoxes/solstices (winter: 6 November to 4 February; spring: 5 February to 6 May; summer: 7 May to 5 August; and autumn: 6 August to 5 November). Participants who reported having arthritis were excluded from analysis. Also, observations missing hs-CRP were excluded from analysis. All data analyses were performed using the SAS ${ }^{\circledR}$ statistical software package version $9 \cdot 2$.

\section{Results}

A total of 519 participants for $24 \mathrm{HR}$ and 586 for 7DDR had at least one clinic visit with hs-CRP data available. After excluding participants with hs-CRP $>10 \mathrm{mg} / \mathrm{l}$, arthritis, BMI $<18.5 \mathrm{~kg} / \mathrm{m}^{2}$ and those missing any of the measurements for the covariates entered in the model, the final sample size for the analysis was 495 for the $24 \mathrm{HR}$ and 559 for the 7DDR with baseline data. The number of followup quarterly measurements available for the $24 \mathrm{HR}$ totalled 1672 (an average of $\approx 3.4$ per participant), and for the 7DDR 1839 (an average of $\approx 3.3$ per participant). Most participants (nearly $75 \%$ ) had both an hs-CRP measurement and at least one $24 \mathrm{HR}$ at three or more measurement points: $12 \%$ had such paired data at one point, $14 \%$ at two points, $20 \%$ at three, $26 \%$ at four and $28 \%$ had paired data at all five points. For hs-CRP and 7DDR, the percentages with both were similar: $14 \%$ with both at one point, $16 \%$ with two, $20 \%$ with three, $26 \%$ with four and $24 \%$ with both at all five points.

Baseline characteristics of the participants are presented by sex (Table 1). The majority of the participants were White, married and working full time. The mean age was 49 (SD 12) years. Compared with females, males were more likely to be overweight, married, working full time and to have a higher level of education.

Energy intake was higher among males than females (difference of $2812 \mathrm{~kJ} / \mathrm{d}(672 \mathrm{kcal} / \mathrm{d})$ for $24 \mathrm{HR}$ and $1456 \mathrm{~kJ} / \mathrm{d}(348 \mathrm{kcal} / \mathrm{d})$ for 7DDR; Table 2). For most 
Table 1 Baseline characteristics of the participants (categorical variables); Dietary Inflammatory Index Development and Testing Study, Columbia, SC, USA, 2011-2012

\begin{tabular}{|c|c|c|c|c|c|c|c|c|c|c|}
\hline \multirow[b]{3}{*}{ Characteristic $^{*}$} & \multicolumn{5}{|c|}{ 24HR-derived data } & \multicolumn{5}{|c|}{ 7DDR-derived data } \\
\hline & \multicolumn{2}{|c|}{ Males ( $n$ 264) } & \multicolumn{2}{|c|}{ Females ( $n$ 231) } & \multirow[b]{2}{*}{$P$ valuet } & \multicolumn{2}{|c|}{ Males ( $n$ 292) } & \multicolumn{2}{|c|}{ Females ( $n$ 267) } & \multirow[b]{2}{*}{$P$ valuet } \\
\hline & $n$ & $\%$ & $n$ & $\%$ & & $n$ & $\%$ & $n$ & $\%$ & \\
\hline Race & & & & & $0 \cdot 72$ & & & & & $0 \cdot 13$ \\
\hline White (Non-Hispanic) & 236 & $89 \cdot 7$ & 205 & $88 \cdot 8$ & & 258 & $89 \cdot 0$ & 225 & $84 \cdot 6$ & \\
\hline Other & 28 & $10 \cdot 3$ & 26 & $11 \cdot 3$ & & 32 & $11 \cdot 0$ & 41 & $15 \cdot 4$ & \\
\hline Current smoker & & & & & $0 \cdot 27$ & & & & & 0.45 \\
\hline Yes & 49 & $18 \cdot 6$ & 37 & $16 \cdot 0$ & & 53 & $18 \cdot 1$ & 42 & $15 \cdot 7$ & \\
\hline No & 215 & $81 \cdot 4$ & 194 & $84 \cdot 0$ & & 239 & $81 \cdot 9$ & 225 & $84 \cdot 3$ & \\
\hline BMI $\left(\mathrm{kg} / \mathrm{m}^{2}\right)$ & & & & & $0 \cdot 01$ & & & & & 0.0005 \\
\hline Normal weight $(>18.5$ to $<25.0)$ & 82 & $31 \cdot 1$ & 102 & $44 \cdot 2$ & & 85 & $29 \cdot 1$ & 120 & $44 \cdot 9$ & \\
\hline Overweight $(25 \cdot 0$ to $<30 \cdot 0)$ & 114 & $43 \cdot 2$ & 80 & $34 \cdot 6$ & & 128 & $44 \cdot 1$ & 91 & $34 \cdot 1$ & \\
\hline Obese $(\geq 30 \cdot 0)$ & 68 & $25 \cdot 8$ & 49 & $21 \cdot 2$ & & 78 & $26 \cdot 7$ & 56 & $21 \cdot 0$ & \\
\hline Marital status & & & & & 0.003 & & & & & 0.003 \\
\hline Single & 26 & $9 \cdot 9$ & 22 & $9 \cdot 5$ & & 29 & $10 \cdot 0$ & 30 & $11 \cdot 2$ & \\
\hline Married/living together & 217 & $82 \cdot 1$ & 169 & $73 \cdot 2$ & & 239 & $82 \cdot 1$ & 195 & $72 \cdot \overline{7}$ & \\
\hline Separated/divorced/widowed & 21 & $8 \cdot 0$ & 40 & $17 \cdot 3$ & & 24 & $7 \cdot 9$ & 43 & $16 \cdot 1$ & \\
\hline Employment status & & & & & 0.0004 & & & & & 0.0002 \\
\hline Full time & 196 & $74 \cdot 2$ & 134 & $58 \cdot 0$ & & 219 & $75 \cdot 0$ & 157 & $58 \cdot 8$ & \\
\hline Part time & 29 & $11 \cdot 0$ & 49 & $21 \cdot 2$ & & 31 & $10 \cdot 6$ & 54 & $20 \cdot 2$ & \\
\hline Unemployed & 39 & $14 \cdot 8$ & 48 & $20 \cdot 8$ & & 42 & $14 \cdot 4$ & 56 & $21 \cdot 0$ & \\
\hline Job type & & & & & $<0.0001$ & & & & & $<0.0001$ \\
\hline Skill or craft & 28 & $12 \cdot 6$ & 14 & $8 \cdot 1$ & & 31 & $12 \cdot 6$ & 13 & $6 \cdot 5$ & \\
\hline Machine operator & 6 & $2 \cdot 7$ & 0 & $0 \cdot 0$ & & 9 & $3 \cdot 6$ & 1 & 0.5 & \\
\hline Manual labour & 15 & $6 \cdot 8$ & 8 & $4 \cdot 6$ & & 20 & $8 \cdot 1$ & 12 & $6 \cdot 0$ & \\
\hline Scientific technical work & 25 & $11 \cdot 3$ & 8 & $4 \cdot 6$ & & 29 & $11 \cdot 7$ & 9 & $4 \cdot 5$ & \\
\hline Service work & 20 & $9 \cdot 0$ & 20 & $11 \cdot 6$ & & 23 & $9 \cdot 3$ & 23 & $11 \cdot 6$ & \\
\hline Clinical, office or sales professional & 16 & $7 \cdot 2$ & 41 & $23 \cdot 7$ & & 18 & $7 \cdot 1$ & 48 & $24 \cdot 1$ & \\
\hline Managerial or administrative work & 112 & $50 \cdot 5$ & 82 & $47 \cdot 4$ & & 117 & $47 \cdot 4$ & 93 & $46 \cdot 7$ & \\
\hline Education & & & & & $<0.0001$ & & & & & $<0.0001$ \\
\hline High school or less & 47 & $17 \cdot 6$ & 84 & $36 \cdot 5$ & & 48 & $16 \cdot 4$ & 90 & $33 \cdot 7$ & \\
\hline Vocational/trade or some college & 69 & $26 \cdot 2$ & 47 & $20 \cdot 4$ & & 83 & $28 \cdot 5$ & 61 & $22 \cdot 9$ & \\
\hline College or more & 148 & $56 \cdot 3$ & 99 & $43 \cdot 0$ & & 161 & $55 \cdot 1$ & 116 & $43 \cdot 4$ & \\
\hline Vitamin/mineral supplements & & & & & 0.005 & & & & & 0.0014 \\
\hline Yes & 63 & $23 \cdot 9$ & 82 & $35 \cdot 5$ & & 69 & $23 \cdot 6$ & 92 & $34 \cdot 5$ & \\
\hline No & 201 & $76 \cdot 1$ & 149 & $64 \cdot 5$ & & 223 & $76 \cdot 4$ & 175 & $65 \cdot 5$ & \\
\hline Alcohol consumption & & & & & $<0.0001$ & & & & & $<0.0001$ \\
\hline Yes & 81 & $30 \cdot 6$ & 26 & $10 \cdot 1$ & & 84 & $28 \cdot 4$ & 29 & $9 \cdot 6$ & \\
\hline No & 180 & $69 \cdot 4$ & 208 & $89 \cdot 9$ & & 207 & $71 \cdot 6$ & 240 & $90 \cdot 4$ & \\
\hline Anti-inflammatory medications & & & & & 0.46 & & & & & $0 \cdot 30$ \\
\hline Yes & 38 & $14 \cdot 4$ & 28 & $12 \cdot 1$ & & 40 & $13 \cdot 7$ & 29 & $10 \cdot 9$ & \\
\hline No & 226 & $85 \cdot 6$ & 203 & $87 \cdot 9$ & & 252 & $86 \cdot 3$ & 238 & $89 \cdot 1$ & \\
\hline
\end{tabular}

24HR, $24 \mathrm{~h}$ diet recall interviews; 7DDR, $7 \mathrm{~d}$ diet recall.

*Some of the categories do not sum to the total because of missing data.

$+P$ value for the $\chi^{2}$ test of the hypothesis that there is no difference between genders.

Table 2 Baseline characteristics of the participants (continuous variables); Dietary Inflammatory Index Development and Testing Study, Columbia, SC, USA, 2011-2012

\begin{tabular}{|c|c|c|c|c|c|c|c|c|c|c|}
\hline \multirow[b]{3}{*}{ Characteristic } & \multicolumn{5}{|c|}{ 24HR-derived data } & \multicolumn{5}{|c|}{ 7DDR-derived data } \\
\hline & \multicolumn{2}{|c|}{ Males ( $n$ 264) } & \multicolumn{2}{|c|}{ Females (n 231) } & \multirow[b]{2}{*}{$P$ value* } & \multicolumn{2}{|c|}{ Males ( $n$ 292) } & \multicolumn{2}{|c|}{ Females ( $n$ 267) } & \multirow[b]{2}{*}{$P$ value } \\
\hline & Mean & SD & Mean & SD & & Mean & SD & Mean & SD & \\
\hline DII & $0 \cdot 11$ & 1.98 & $0 \cdot 75$ & $2 \cdot 14$ & 0.01 & 0.52 & $2 \cdot 0$ & 0.95 & 1.9 & 0.01 \\
\hline Age (years) & $49 \cdot 3$ & $12 \cdot 3$ & $48 \cdot 4$ & $11 \cdot 7$ & 0.43 & $48 \cdot 5$ & $12 \cdot 5$ & $47 \cdot 3$ & $12 \cdot 0$ & 0.24 \\
\hline Serum hs-CRP (mg/l) & $2 \cdot 4$ & $4 \cdot 6$ & $2 \cdot 2$ & $5 \cdot 7$ & 0.73 & $2 \cdot 3$ & $4 \cdot 4$ & $2 \cdot 2$ & $5 \cdot 1$ & 0.75 \\
\hline Total physical activity (MET-h/d) & $32 \cdot 0$ & $7 \cdot 4$ & $29 \cdot 1$ & 3.9 & $<0.0001$ & $32 \cdot 1$ & $7 \cdot 7$ & 28.9 & 03.9 & $<0.0001$ \\
\hline Energy intake $(\mathrm{kJ} / \mathrm{d})$ & 9464 & 3335 & 6653 & 1531 & $<0.0001$ & 9042 & 3623 & 7586 & 4075 & $<0.0001$ \\
\hline Energy intake (kcal/d) & 2262 & 797 & 1590 & 366 & $<0.0001$ & 2161 & 866 & 1813 & 974 & $<0.0001$ \\
\hline $\mathrm{HDL}-\mathrm{C}(\mathrm{mg} / \mathrm{dl})$ & $43 \cdot 4$ & $11 \cdot 3$ & $51 \cdot 3$ & $12 \cdot 3$ & $<0.0001$ & $43 \cdot 2$ & $11 \cdot 0$ & $51 \cdot 7$ & $12 \cdot 9$ & $<0.0001$ \\
\hline $\mathrm{SBP}(\mathrm{mmHg})$ & $126 \cdot 8$ & $18 \cdot 1$ & $113 \cdot 7$ & 18 & $<0.0001$ & $126 \cdot 7$ & $18 \cdot 0$ & $113 \cdot 3$ & $17 \cdot 2$ & $<0.0001$ \\
\hline
\end{tabular}

24HR, $24 \mathrm{~h}$ diet recall interviews; 7DDR, $7 \mathrm{~d}$ diet recall; DII, Dietary Inflammatory Index; hs-CRP, high-sensitivity C-reactive protein; MET, metabolic equivalents of task (a physiological measure expressing the energy cost of physical activities); HDL-C, HDL-cholesterol; SBP, systolic blood pressure.

${ }^{*} P$ value for the two-sample $t$ test of the hypothesis that there is no difference between genders. 
nutrients, males had a significantly higher intake compared with females, largely because of their higher energy intake. Females had a significantly higher intake of vitamin or mineral supplements (Table 1). No difference was found in herbal supplement use and very few participants consumed fish-oil supplements (three participants in total). Approximately $13.5 \%$ of the study population was using anti-inflammatory drugs at baseline in the $24 \mathrm{HR}$ subset compared with $12.5 \%$ of those in the 7DDR subset (this was controlled for during analysis). Across all time points, the DII score ranged from $5 \cdot 8$ to $-5 \cdot 4$ for the 24HR subset and from $4 \cdot 3$ to $-5 \cdot 3$ for the 7DDR subset, which represents about $67 \%$ and $57 \%$, respectively, of the range observed in the eleven-country data set used as our standard referent ${ }^{(50)}$. Mean DII score for the $24 \mathrm{HR}$ subset was $0 \cdot 18$ (SD $2 \cdot 18$ ) and the mean DII score for the 7DDR subset was $0 \cdot 84$ (SD 2.0).

As presented in Table 3, tests for trends across DII tertiles revealed significant increasing trends for hs-CRP $(P<0.0001$ in both 24HR and 7DDR subsets), BMI $(P<0.0001$ in the 24HR subset and $P=0.002$ in the 7DDR subset) and serum LDL-cholesterol $(P=0.009$ for 24HR and $P<0.0001$ for 7DDR) while a significant decreasing trend was observed for total physical activity (MET-h/d) in the 24HR subset $(P<0 \cdot 0001)$.

\section{Analysis of high-sensitivity C-reactive protein as dichotomous}

As recommended by the CDC and the American Heart Association, we dichotomized hs-CRP at the level of $3 \mathrm{mg} / \mathrm{l}$, considering measurements greater than this level at higher CVD risk ${ }^{(60)}$. A total of 302 observations (18\% of the total 1672 observations) for $24 \mathrm{HR}$ and 323 observations (18\% of the total of 1839 observations) for 7DDR had an elevated hs-CRP; i.e. $>3 \mathrm{mg} / \mathrm{l}$. Unadjusted analysis with continuous DII as the independent variable yielded significant results in both the 24HR and 7DDR subsets $(\mathrm{OR}=1 \cdot 06 ; 95 \% \mathrm{CI} 1 \cdot 00,1 \cdot 12$ for $24 \mathrm{HR}$ and $\mathrm{OR}=1 \cdot 10$; $95 \%$ CI $1 \cdot 03,1 \cdot 17$ for 7 DDR). Results from adjusted analysis revealed a significant association between DII score and elevated hs-CRP; a 1-point increase in score was associated with an increased odds of elevated hs-CRP for both subgroups $(\mathrm{OR}=1 \cdot 08$; $95 \%$ CI $1 \cdot 01,1 \cdot 16$ for $24 \mathrm{HR}$ and $\mathrm{OR}=1 \cdot 10 ; 95 \%$ CI $1.02,1 \cdot 19$ for 7DDR; Table 4). Analysis with DII as tertiles revealed significant associations between DII in tertiles 3 and 2, compared with tertile 1 (tertile $3 v \cdot 1$, OR $=1 \cdot 47 ; 95 \%$ CI $1 \cdot 03,2 \cdot 12$; tertile $2 v \cdot 1, \mathrm{OR}=1 \cdot 35 ; 95 \% \mathrm{CI} 1 \cdot 01,1 \cdot 81$ ) for the $24 \mathrm{HR}$ subset, whereas for the 7DDR subset a significant association was seen between tertile 3 and tertile $1(\mathrm{OR}=1 \cdot 61$; $95 \% \mathrm{CI} 1 \cdot 15,2 \cdot 27)$. In addition, age, HDL-cholesterol and absence of an infection during the study quarter were significantly associated with hs-CRP in both subsets. Overweight and obese individuals had significantly higher odds of an elevated hs-CRP compared with normal-weight individuals. No other variable entered into

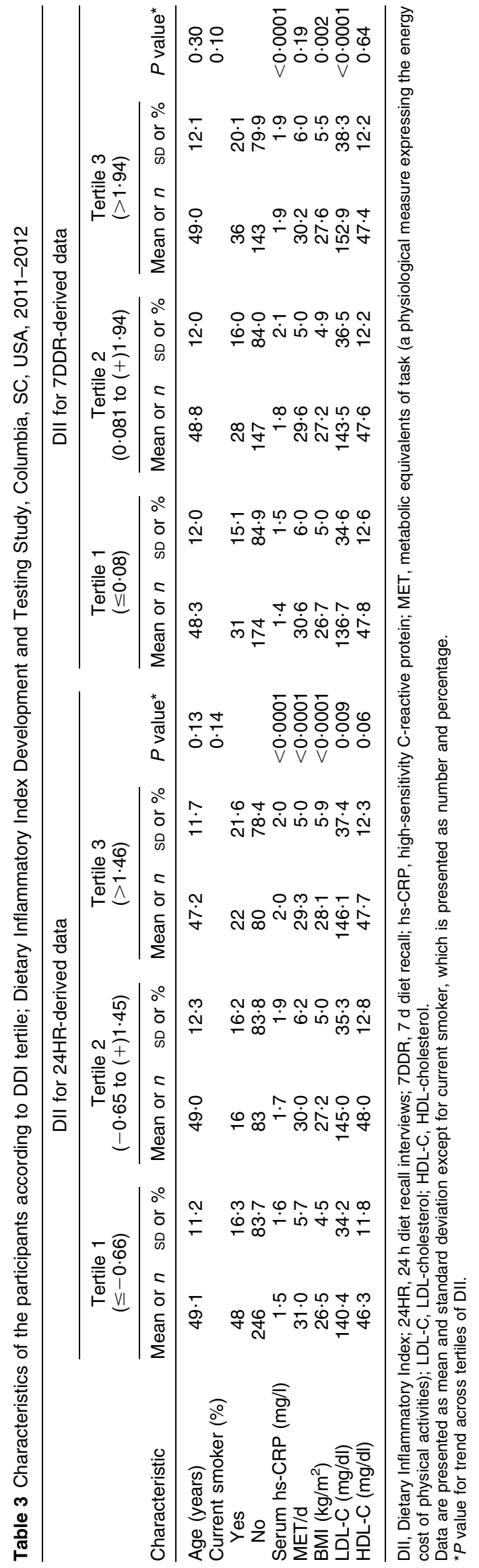


Table 4 Summary of logistic regression analysis based on hs-CRP as a dichotomous variable ( $\leq 3 \mathrm{mg} / \mathrm{l}$, $>3 \mathrm{mg} / \mathrm{l})$; Dietary Inflammatory Index Development and Testing Study, Columbia, SC, USA, 2011-2012

\begin{tabular}{|c|c|c|c|c|c|c|c|c|}
\hline \multirow[b]{3}{*}{ Variables } & \multicolumn{4}{|c|}{$24 \mathrm{HR}$-derived data } & \multicolumn{4}{|c|}{ 7DDR-derived data } \\
\hline & \multicolumn{2}{|c|}{ Unadjusted } & \multicolumn{2}{|c|}{ Adjusted $^{*}$} & \multicolumn{2}{|c|}{ Unadjusted } & \multicolumn{2}{|c|}{ Adjusted $^{*}$} \\
\hline & OR & $95 \% \mathrm{Cl}$ & OR & $95 \% \mathrm{Cl}$ & OR & $95 \% \mathrm{Cl}$ & OR & $95 \% \mathrm{Cl}$ \\
\hline $\begin{array}{l}\text { DII (continuous) } \\
\text { DIl (tertiles) }\end{array}$ & $1 \cdot 06$ & $1 \cdot 00,1 \cdot 12$ & $1 \cdot 08$ & $1 \cdot 01,1 \cdot 16$ & $1 \cdot 10$ & $1 \cdot 03,1 \cdot 17$ & $1 \cdot 10$ & $1 \cdot 02,1 \cdot 19$ \\
\hline $\begin{array}{l}\text { Tertile } 2 v \text {. tertile } 1 \\
\text { Tertile } 3 v \text {. tertile } 1\end{array}$ & $\begin{array}{l}1 \cdot 27 \\
1 \cdot 32\end{array}$ & $\begin{array}{l}0.98,1.64 \\
0.98,1.79\end{array}$ & $\begin{array}{l}1 \cdot 35 \\
1.47\end{array}$ & $\begin{array}{l}1 \cdot 01,1 \cdot 81 \\
1 \cdot 03,2 \cdot 12\end{array}$ & $\begin{array}{l}1 \cdot 14 \\
1 \cdot 96\end{array}$ & $\begin{array}{l}0.85,1.49 \\
1.43,2.63\end{array}$ & $\begin{array}{l}1.02 \\
1.61\end{array}$ & $\begin{array}{l}0 \cdot 76,1 \cdot 34 \\
1 \cdot 15,2 \cdot 27\end{array}$ \\
\hline
\end{tabular}

hs-CRP, high-sensitivity C-reactive protein; 24HR, $24 \mathrm{~h}$ diet recall interviews; 7DDR, $7 \mathrm{~d}$ diet recall; DII, Dietary Inflammatory Index.

${ }^{*}$ Results (odds ratios and associated $95 \%$ confidence intervals) shown are obtained from the logistic regression model, which controlled for all variables shown with additional control for MET (metabolic equivalents of task), gender, light season, race, marital status, serum total cholesterol, employment status, antiinflammatory medication use, alcohol status and herbal supplement use.

the model was significantly associated with hs-CRP. We examined the association between DII score and the dichotomous hs-CRP with stratification by infection status. The effect of the DII score was not different among those with $v$. without an infection; therefore, we reported only the overall odds ratios here. A 5-point increase in the 24HR-derived DII score was associated with $\approx 50 \%$ increase in the odds of an elevated hs-CRP (OR $=1 \cdot 47$; $95 \%$ CI $1 \cdot 03,2 \cdot 10$ ), while a 10-point increase more than doubled the odds (OR $=2 \cdot 15 ; 95 \%$ CI $1 \cdot 06,4 \cdot 40)$. Similarly, a 5-point increase in the 7DDR-derived score was associated with a $60 \%$ increase in the odds of an elevated hs-CRP (OR = 1.60; 95\% CI 1·09, 2·36), while a 10 -point increase more than doubled the odds ratio (OR $=2 \cdot 56 ; 95 \%$ CI $1 \cdot 18,5 \cdot 56)$. This new populationbased DII was more highly correlated with hs-CRP $(r=0 \cdot 11, P<0 \cdot 0001)$ than was the old DII $(r=0 \cdot 04$, $P=0 \cdot 08)$.

\section{Discussion}

Updating the literature database and refinement of the scoring algorithms for the DII appeared to increase construct validation in SEASONS, a study ideally suited for this purpose because of carefully collected dietary exposure (i.e. multiple $24 \mathrm{HR}$ and 7DDR) and hs-CRP measures demarcating the four seasons of the year in adult female and male participants. We were able to predict hs-CRP levels $\leq 3 \mathrm{mg} / 1 \quad v$. $>3 \mathrm{mg} / \mathrm{l}$ using the DII applied to the dietary assessment methods in SEASONS.

Because an hs-CRP value of $>3 \mathrm{mg} / 1$ is recommended as a relevant clinical cut-off point for identifying individuals at high CVD risk ${ }^{(60)}$, we were particularly interest in the association between the DII and hs-CRP as a dichotomous variable. Using multiple $24 \mathrm{HR}$-derived data, we found that a pro-inflammatory diet, as defined by the DII, was associated with an increase in the odds of an elevated hs-CRP $(>3 \mathrm{mg} / \mathrm{l})$. We also were very interested in whether there would be a large drop-off in predictive ability in going from multiple $24 \mathrm{HR}$, which are too expensive to be used in most epidemiological studies, to use of a structured questionnaire typical of larger-scale studies. Even though the total number of food parameters used to compute the DII for the 7DDR is less than that used for the DII applied to the 24HR (twenty-eight $v$. forty-four), there was uniform distribution of pro- and anti-inflammatory food parameters in the available data and, most importantly, virtually no degradation in predictive ability. In all models, we controlled for age ${ }^{(61)}$ and $\mathrm{BMI}^{(62,63)}$, which are known predictors of CRP.

Despite its racial homogeneity (consisting of $\sim 90 \%$ non-Hispanic Whites), there are a number of strengths in using SEASONS. It is one of the few studies where both multiple-day $24 \mathrm{HR}$ and structured questionnaire were used to collect dietary data. The $24 \mathrm{HR}$ is the most accurate method for measuring macronutrient and micronutrient intakes, owing to its ability to assess intake of foods, such as spices, that are not commonly found on structured instruments but which may have a substantial effect on inflammation despite that they tend to be consumed in small quantities in the USA ${ }^{(64)}$. Like most such structured instruments, the 7DDR, with its focus on long-term intake of macronutrients especially dietary fat, did not measure such foods. Still, its predictive ability seems unimpaired; perhaps owing to the infrequency of consuming these foods in this population.

Another strength of the SEASONS is that the sample size is large for both data subsets, thus providing a robust estimate of the association between the DII and hs-CRP. Within SEASONS, there also is a wealth of information collected at each time point. This allowed appropriate control for a number of other variables, which in turn decreased the possibility of uncontrolled confounding as an explanation for our results.

It is important to note that SEASONS is an observational study; therefore, it is remarkable to observe significant prediction of interval changes in hs-CRP by the DII in the absence of an intervention. Despite that it focuses mainly on White Americans, the values obtained from the $24 \mathrm{HR}$ and the 7DDR in SEASONS represent a wide range of the global range of the DII (i.e. $67 \%$ and $57 \%$, respectively) ${ }^{(50)}$. 
In summary, we found that the DII was able to predict odds of having an elevated hs-CRP in SEASONS, a longitudinal study with high-quality dietary and inflammation-related data obtained at baseline and at the end of each of four seasons over a year, using both the 24HR- and 7DDR-derived dietary data.

\section{Acknowledgements}

Sources of funding: This work was supported by the South Carolina Statewide Cancer Prevention and Control Program Research Fund and the National Heart, Lung, and Blood Institute (grant \#1R01 HL073194, SEASONS Study; Principal Investigator I.S.O.). J.R. Hébert was supported by an Established Investigator Award in Cancer Prevention and Control from the Cancer Training Branch of the National Cancer Institute (K05 CA136975). Y.M. was supported by grant \#1R01HL094575-01A1 from the National Heart, Lung, and Blood Institute. The National Heart, Lung, and Blood Institute and the National Cancer Institute had no role in the design, analysis or writing of this article. Conflicts of interest: None of the authors declares a conflict of interest. The SEASONS was approved by the University of Massachusetts Institutional Review Board but for the purpose of the current analysis the Institutional Review Board approval was exempt. Authors' contributions: N.S. was involved in the design of the DII, analysed data from SEASONS and collaborated with J.R. Hébert in writing the original draft of the paper; S.E.S. was involved in design of the DII and provided critical input in revising drafts of the paper; T.G.H. was involved in the design of the DII, provided statistical expertise and helped to write the paper; J.R. Hussey was involved in analysing the data, provided high-level statistical expertise and input in writing the paper; Y.M. provided consultation on analysing the SEASONS data and participated in writing the paper; I.S.O. provided high-level consultation on the SEASONS and input in writing the paper; F.T. provided consultation to N.S. in fitting the models and input in writing the paper; J.R. Hébert devised the initial DII concept, guided all phases of the design of the DII, supervised the analysis of the data used in validating the DII and took the lead in writing the paper.

\section{References}

1. Keibel A, Singh V \& Sharma MC (2009) Inflammation, microenvironment, and the immune system in cancer progression. Curr Pharm Des 15, 1949-1955.

2. Terzic J, Grivennikov S, Karin E et al. (2010) Inflammation and colon cancer. Gastroenterology 138, 2101-2114.e5.

3. Jackson L \& Evers BM (2006) Chronic inflammation and pathogenesis of GI and pancreatic cancers. Cancer Treat Res 130, 39-65.

4. Erlinger TP, Platz EA, Rifai N et al. (2004) C-reactive protein and the risk of incident colorectal cancer. JAMA 291, 585-590.
5. Ridker PM, Glynn RJ \& Hennekens CH (1998) C-reactive protein adds to the predictive value of total and HDL cholesterol in determining risk of first myocardial infarction. Circulation 97, 2007-2011.

6. Ridker PM, Rifai N, Rose L et al. (2002) Comparison of C-reactive protein and low-density lipoprotein cholesterol levels in the prediction of first cardiovascular events. $N$ Engl J Med 347, 1557-1565.

7. Hermsdorff HH, Zulet MA, Puchau B et al. (2011) Central adiposity rather than total adiposity measurements are specifically involved in the inflammatory status from healthy young adults. Inflammation 34, 161-170.

8. Bastard JP, Jardel C, Bruckert E et al. (2000) Elevated levels of interleukin 6 are reduced in serum and subcutaneous adipose tissue of obese women after weight loss. J Clin Endocrinol Metab 85, 3338-3342.

9. Ridker PM, Buring JE, Cook NR et al. (2003) C-reactive protein, the metabolic syndrome, and risk of incident cardiovascular events: an 8-year follow-up of 14719 initially healthy American women. Circulation 107, 391-397.

10. Hermsdorff HH, Zulet MA, Puchau B et al. (2010) Fruit and vegetable consumption and proinflammatory gene expression from peripheral blood mononuclear cells in young adults: a translational study. Nutr Metab (Lond) 7, 42.

11. Esmaillzadeh A, Kimiagar M, Mehrabi Y et al. (2007) Dietary patterns and markers of systemic inflammation among Iranian women. J Nutr 137, 992-998.

12. Dalziel K, Segal L \& de Lorgeril M (2006) A Mediterranean diet is cost-effective in patients with previous myocardial infarction. J Nutr 136, 1879-1885.

13. Chrysohoou C, Panagiotakos DB, Pitsavos C et al. (2004) Adherence to the Mediterranean diet attenuates inflammation and coagulation process in healthy adults: the ATTICA Study. J Am Coll Cardiol 44, 152-158.

14. Esposito K, Marfella R, Ciotola M et al. (2004) Effect of a Mediterranean-style diet on endothelial dysfunction and markers of vascular inflammation in the metabolic syndrome: a randomized trial. JAMA 292, 1440-1446.

15. Estruch R, Martinez-Gonzalez MA, Corella D et al. (2006) Effects of a Mediterranean-style diet on cardiovascular risk factors: a randomized trial. Ann Intern Med 145, 1-11.

16. Serrano-Martinez $\mathrm{M}$, Palacios $\mathrm{M}$, Martinez-Losa $\mathrm{E}$ et al. (2005) A Mediterranean dietary style influences TNF- $\alpha$ and VCAM-1 coronary blood levels in unstable angina patients. Eur J Nutr 44, 348-354.

17. Gao X, Bermudez OI \& Tucker KL (2004) Plasma C-reactive protein and homocysteine concentrations are related to frequent fruit and vegetable intake in Hispanic and nonHispanic white elders. J Nutr 134, 913-918.

18. Watzl B, Kulling SE, Moseneder J et al. (2005) A 4-wk intervention with high intake of carotenoid-rich vegetables and fruit reduces plasma C-reactive protein in healthy, nonsmoking men. Am J Clin Nutr 82, 1052-1058.

19. Esmaillzadeh A, Kimiagar M, Mehrabi Y et al. (2006) Fruit and vegetable intakes, C-reactive protein, and the metabolic syndrome. Am J Clin Nutr 84, 1489-1497.

20. Ferrucci L, Cherubini A, Bandinelli S et al. (2006) Relationship of plasma polyunsaturated fatty acids to circulating inflammatory markers. J Clin Endocrinol Metab 91, 439-446.

21. Lopez-Garcia E, Schulze MB, Manson JE et al. (2004) Consumption of $(n-3)$ fatty acids is related to plasma biomarkers of inflammation and endothelial activation in women. J Nutr 134, 1806-1811.

22. Niu K, Hozawa A, Kuriyama S et al. (2006) Dietary longchain $n-3$ fatty acids of marine origin and serum C-reactive protein concentrations are associated in a population with a diet rich in marine products. Am J Clin Nutr 84, 223-229.

23. Zampelas A, Panagiotakos DB, Pitsavos C et al. (2005) Fish consumption among healthy adults is associated with decreased levels of inflammatory markers related to 
cardiovascular disease: the ATTICA study. J Am Coll Cardiol 46, 120-124.

24. Zhao G, Etherton TD, Martin KR et al. (2004) Dietary $\alpha$-linolenic acid reduces inflammatory and lipid cardiovascular risk factors in hypercholesterolemic men and women. J Nutr 134, 2991-2997.

25. Gunter MJ, Stolzenberg-Solomon R, Cross AJ et al. (2006) A prospective study of serum C-reactive protein and colorectal cancer risk in men. Cancer Res 66, 2483-2487.

26. Bo S, Durazzo M, Guidi S et al. (2006) Dietary magnesium and fiber intakes and inflammatory and metabolic indicators in middle-aged subjects from a population-based cohort. Am J Clin Nutr 84, 1062-1069.

27. King DE, Egan BM \& Geesey ME (2003) Relation of dietary fat and fiber to elevation of C-reactive protein. $A m J$ Cardiol 92, 1335-1339.

28. Ajani UA, Ford ES \& Mokdad AH (2004) Dietary fiber and C-reactive protein: findings from national health and nutrition examination survey data. J Nutr 134, 1181-1185.

29. King DE, Egan BM, Woolson RF et al. (2007) Effect of a high-fiber diet vs a fiber-supplemented diet on C-reactive protein level. Arch Intern Med 167, 502-506.

30. Ma Y, Griffith JA, Chasan-Taber L et al. (2006) Association between dietary fiber and serum C-reactive protein. $\mathrm{Am} \mathrm{J}$ Clin Nutr 83, 760-766.

31. Avellone G, Di Garbo V, Campisi D et al. (2006) Effects of moderate Sicilian red wine consumption on inflammatory biomarkers of atherosclerosis. Eur J Clin Nutr 60, 41-47.

32. Sierksma A, van der Gaag MS, Kluft C et al. (2002) Moderate alcohol consumption reduces plasma C-reactive protein and fibrinogen levels; a randomized, diet-controlled intervention study. Eur J Clin Nutr 56, 1130-1136.

33. Imhof A, Froehlich M, Brenner $\mathrm{H}$ et al. (2001) Effect of alcohol consumption on systemic markers of inflammation. Lancet 357, 763-767.

34. van Herpen-Broekmans WM, Klopping-Ketelaars IA, Bots ML et al. (2004) Serum carotenoids and vitamins in relation to markers of endothelial function and inflammation. Eur $J$ Epidemiol 19, 915-921.

35. Bertran N, Camps J, Fernandez-Ballart J et al. (2005) Diet and lifestyle are associated with serum C-reactive protein concentrations in a population-based study. J Lab Clin Med 145, 41-46.

36. Upritchard JE, Sutherland WH \& Mann JI (2000) Effect of supplementation with tomato juice, vitamin E, and vitamin $\mathrm{C}$ on LDL oxidation and products of inflammatory activity in type 2 diabetes. Diabetes Care 23, 733-738.

37. Devaraj S, Li D \& Jialal I (1996) The effects of $\alpha$ tocopherol supplementation on monocyte function. Decreased lipid oxidation, interleukin $1 \beta$ secretion, and monocyte adhesion to endothelium. J Clin Invest 98, 756-763.

38. van Tits LJ, Demacker PN, de Graaf J et al. (2000) $\alpha$-Tocopherol supplementation decreases production of superoxide and cytokines by leukocytes ex vivo in both normolipidemic and hypertriglyceridemic individuals. $A m J$ Clin Nutr 71, 458-464.

39. Devaraj S \& Jialal I (2000) $\alpha$-Tocopherol supplementation decreases serum C-reactive protein and monocyte interleukin-6 levels in normal volunteers and type 2 diabetic patients. Free Radic Biol Med 29, 790-792.

40. Murphy RT, Foley JB, Tome MT et al. (2004) Vitamin E modulation of C-reactive protein in smokers with acute coronary syndromes. Free Radic Biol Med 36, 959-965.

41. Chien CT, Chang WT, Chen HW et al. (2004) Ascorbate supplement reduces oxidative stress in dyslipidemic patients undergoing apheresis. Arterioscler Thromb Vasc Biol 24, 1111-1117.

42. Korantzopoulos P, Kolettis TM, Kountouris E et al. (2005) Oral vitamin $\mathrm{C}$ administration reduces early recurrence rates after electrical cardioversion of persistent atrial fibrillation and attenuates associated inflammation. Int $J$ Cardiol 102, 321-326.

43. Wannamethee SG, Lowe GD, Rumley A et al. (2006) Associations of vitamin C status, fruit and vegetable intakes, and markers of inflammation and hemostasis. Am J Clin Nutr 83, 567-574.

44. Folsom AR, Desvarieux M, Nieto FJ et al. (2003) B vitamin status and inflammatory markers. Atherosclerosis 169, 169-174.

45. Erlinger TP, Guallar E, Miller ER 3rd et al. (2001) Relationship between systemic markers of inflammation and serum ß-carotene levels. Arch Intern Med 161, 1903-1908.

46. Kritchevsky SB, Bush AJ, Pahor M et al. (2000) Serum carotenoids and markers of inflammation in nonsmokers. Am J Epidemiol 152, 1065-1071.

47. King DE, Mainous AG 3rd, Geesey ME et al. (2005) Dietary magnesium and C-reactive protein levels. J Am Coll Nutr 24, 166-171.

48. Song Y, Li TY, van Dam RM et al. (2007) Magnesium intake and plasma concentrations of markers of systemic inflammation and endothelial dysfunction in women. Am J Clin Nutr 85, 1068-1074.

49. Song Y, Ridker PM, Manson JE et al. (2005) Magnesium intake, C-reactive protein, and the prevalence of metabolic syndrome in middle-aged and older US women. Diabetes Care 28, 1438-1444.

50. Shivappa N, Steck SE, Hurley TG et al. (2013) Designing and developing a literature-derived, population-based dietary inflammatory index. Public Health Nutr (Epublication ahead of print version).

51. Cavicchia PP, Steck SE, Hurley TG et al. (2009) A new dietary inflammatory index predicts interval changes in high-sensitivity C-reactive protein. J Nutr 139, 2365-2372.

52. Merriam PA, Ockene IS, Hebert JR et al. (1999) Seasonal variation of blood cholesterol levels: study methodology. J Biol Rhythms 14, 330-339.

53. Ockene IS, Chiriboga DE, Stanek EJ 3rd et al. (2004) Seasonal variation in serum cholesterol levels: treatment implications and possible mechanisms. Arch Intern Med 164, 863-870.

54. Hebert JR, Ockene IS, Hurley TG et al. (1997) Development and testing of a seven-day dietary recall. J Clin Epidemiol 50, 925-937.

55. Hebert JR, Ebbeling CB, Ockene IS et al. (1999) A dietitiandelivered group nutrition program leads to reductions in dietary fat, serum cholesterol, and body weight: findings from the Worcester Area Trial for Counseling in Hyperlipidemia (WATCH). J Am Diet Assoc 99, 544-552.

56. Ockene IS, Hebert JR, Ockene JK et al. (1999) Effect of physician-delivered nutrition counseling training and an office support system on saturated fat intake, weight, and serum lipid measurements in a hyperlipidemic population: the Worcester-Area Trial for Counseling in Hyperlipidemia (WATCH). Arch Intern Med 159, 725-731.

57. Matthews CE, Hebert JR, Freedson P et al. (2000) Comparing physical activity assessment methods in the Seasonal Variation of Blood Cholesterol Study. Med Sci Sports Exer 32, 976-984.

58. Ockene IS, Matthews CE, Rifai N et al. (2001) Variability and classification accuracy of serial high-sensitivity C-reactive protein measurements in healthy adults. Clin Chem $\mathbf{4 7}$, 444-450.

59. Friedewald WT, Levy RI \& Frederickson DS (1972) Estimation of plasma low-density lipoprotein cholesterol concentration without use of the preparative ultracentrifuge. Clin Chem 18, 499-502.

60. Pearson TA, Mensah GA, Alexander RW et al. (2003) Markers of inflammation and cardiovascular disease: application to clinical and public health practice: a statement for healthcare professionals from the Centers for Disease Control and Prevention and the American Heart Association. Circulation 107, 499-511. 
61. Khor LL, Muhlestein JB, Carlquist JF et al. (2004) Sex- and age-related differences in the prognostic value of $\mathrm{C}$-reactive protein in patients with angiographic coronary artery disease. Am J Med 117, 657-664.

62. Ma Y, Chiriboga DE, Pagoto SL et al. (2011) Association between depression and C-reactive protein. Cardiol Res Pract 2011, 286509.
63. Wee CC, Mukamal KJ, Huang A et al. (2008) Obesity and C-reactive protein levels among white, black, and Hispanic US adults. Obesity (Silver Spring) 16, 875-880.

64. Hebert JR, Hurley TG, Chiraboga DE et al. (1998) A comparison of selected nutrient intakes derived from three diet assessment methods used in a low-fat maintenance trial. Public Health Nutr 1, 207-214. 